\title{
A STUDY OF PHYSICAL ACTIVITY LEVELS AND QUALITY OF LIFE IN YOUNG ADULTS DURING THE COVID-19 PANDEMIC
}

DOI: 10.36740/WLek202106122

\author{
Mariia A. Ovdii', Kateryna M. Solomakha' ${ }^{1}$, Mykola 0. Yasynetskyi' ${ }^{1}$, Nataliia P. Ponomarenko² ${ }^{2}$ Yurii M. Rydzel$^{2}$ \\ '0.0. BOGOMOLETS NATIONAL MEDICAL UNIVERSITY, KYIV, UKRAINE \\ ${ }^{2}$ CHERNIHIV NATIONAL UNIVERSITY OF TECHNOLOGY, CHERNIHIV, UKRAINE
}

\begin{abstract}
The aim: To investigate the impact of the COVID-19 pandemic on the level of physical activity and quality of life in young adults.

Materials and methods: A survey of 327 young people aged 18-25 years was conducted; the SF-36 (Medical Outcomes Study-Short Form) questionnaire was used to determine the quality of life; a questionnaire taking into account theWHO Global Recommendations on Physical Activity for Health in order to determine the level of physical activity was applied. Results: Young adults men $88(27 \%)$ and 239 women (73\%), mean age $21.4 \pm 1.8$ y.0., the survey showed that $52 \%$ of those studied did not engage in physical activity at all, $28 \%$ had insufficient physical activity, only $20 \%$ had an adequate level of physical activity. There was a decrease in all quality of life indicators during the pandemic period compared to the previous period, especially the physical role functioning indicator $(p=0.0002)$, general health $(p=0.0004)$, emotional role functioning indicator $(p=0.0001)$ and mental health indicator $(p=0.0004)$.

Conclusions: The COVID-19 pandemic has had a significant impact on the quality of life and physical activity levels of young adults and most of this is due to the restrictive measures of the pandemic.
\end{abstract}

KEY WORDS: COVID-19 pandemic, quality of life, physical activity, young adults

Wiad Lek. 2021;74(6):1405-1408

\section{INTRODUCTION}

Physical activity (PA) is any arbitrary movement of the body by skeletal muscles and requires energy expenditure. PA includes all types of active recreation, sports, recreational training, activity during household chores and activity at work. Regular physical activity is the main sign of a healthy lifestyle $[1,2]$. The World Health Organization (WHO) identifies regular PA as a key factor in the prevention of non-communicable diseases. Studies confirm that regular PA is associated with a reduced risk of premature death and for a number of diseases, such as heart disease, stroke, diabetes and several types of cancer. On the contrary, people with inadequate levels of PA have a 20-30\% increased risk of death compared to people who are sufficiently active $[2,3]$. To get the full benefits of regular $\mathrm{PA}$, the WHO recommends at least 150-300 minutes of moderate to moderate-intensity aerobic PA per week for people aged 18-64 years. It is this range of PA associated with a clear dose-response relationship between PA, health and risk reduction $[1,4,5]$.

The modern world has encountered the COVID-19 pandemic, which in turn has led to significant changes in society, lifestyle, physical activity levels and quality of life $[6,7]$. The COVID-19 pandemic has significantly limited the physical activity of people of different age groups, certainly further affecting mental and physical health levels. A recent study also suggests that there are underlying problems with sleep and psychological disorders (e.g., stress, anxiety, depression) associated with decreased physical activity, as well as decreased social interaction $[8,9]$. To stop the virus spread, strict restrictive measures have been introduced in almost all countries of the world - quarantine, social distancing, distance learning. The question of how young people are reacting to the above restrictions and how pandemic restrictive measures affect their level of physical activity and quality of life needs to be studied in more detail [10].

\section{THE AIM}

The aim of our work was to investigate how COVID-19 pandemic affects the level of physical activity and quality of life in young adults.

\section{MATERIALS AND METHODS}

The object of our study was 327 people aged 18-25 years. All subjects were asked to complete a survey about their level of physical activity; the questionnaire was formed taking into account the WHO Global Recommendations on Physical Activity for Health for people aged 18-64 years, where it is recommended to get engaged in physical activ- 
Table I. The physical component of health depending on the period.

\begin{tabular}{cccc}
\hline \multirow{2}{*}{ Scales of the SF-36 quality of life questionnaire, in points } & \multicolumn{3}{c}{ Groups } \\
\cline { 2 - 4 } & Before pandemic & During pandemic & p \\
\hline PF & $95,7 \pm 4,8$ & $92,1 \pm 8,4$ & $0,007^{*}$ \\
\hline RF & $93,2 \pm 9,3$ & $83,2 \pm 12,3$ & $0,0002^{*}$ \\
\hline PI & $88,4 \pm 7,2$ & $86,8 \pm 10,6$ & 0,357 \\
\hline GH & $72,5 \pm 8,4$ & $65,3 \pm 11,3$ & $0,0004^{*}$ \\
\hline PCH & $55,8 \pm 8,9$ & $52,4 \pm 7,8$ & $0,033^{*}$ \\
\hline
\end{tabular}

Notes: PF - physical functioning; RF - role functioning due to physical condition; PI - pain intensity; GH - general health; PCH - the physical component of health; ${ }^{*}$ - statistically significant result.

Table II. Psychological component of health depending on the period.

\begin{tabular}{cccc}
\hline \multirow{2}{*}{ Scales of the SF-36 quality of life questionnaire in points } & \multicolumn{3}{c}{ Groups } \\
\cline { 2 - 4 } & Before pandemic & During pandemic & p \\
\hline RF & $83,3 \pm 9,8$ & $64,1 \pm 10,4$ & $0,0001^{*}$ \\
\hline VA & $68,2 \pm 5,3$ & $66,1 \pm 7,3$ & 0,086 \\
\hline SF & $82,4 \pm 7,2$ & $79,8 \pm 8,6$ & 0,087 \\
\hline MH & $73,1 \pm 8,4$ & $61,3 \pm 11,3$ & $0,0004^{*}$ \\
\hline PCH & $51,3 \pm 8,9$ & $48,4 \pm 7,8$ & 0,068 \\
\hline
\end{tabular}

Notes: PF - role functioning due to emotions; VA - vital activity; SF - social functioning; MH - mental health; PCH - a psychological component of health;

* - statistically significant result.

ity for more than 150 min per week in order to maintain health [2]. The quality of life questionnaire was administered using the SF-36 quality of life questionnaire (Medical Outcomes Study-Short Form) [11]. The survey results were used to calculate 8 parameters: physical functioning, role functioning, pain intensity, general health, emotional functioning, vitality, social functioning, and psychological functioning. Each parameter was assessed on a scale from 0 to 100 points, with the lower the number of points, the worse the quality of life. Anthropometric parameters were assessed: height, body weight, and body mass index (BMI), BMI was calculated as the ratio of body weight $(\mathrm{kg})$ to height $\left(\mathrm{m}^{2}\right)$, and the results were interpreted taking into account WHO recommendations [2]. Statistical analysis of the results was performed using a package of licensed programs «Statistica». Data were presented as numbers, percentages (\%), mean or median (interquartile range), respectively. $\mathrm{p}$ value $\leq 0.05$ was interpreted as statistically significant.

Ethics: Written informed consents were obtained from the parents or the caregiver before collecting samples.

\section{RESULTS}

We interviewed 327 young people, including 88 male (27\%) and 239 female (73\%) subjects, the average age was $21.4 \pm 1.8$ years. In assessing BMI it was found that $68 \%$ of the students had normal weight, $5 \%$ were underweight, $26 \%$ were overweight, $1 \%$ of the subjects had first-degree obesity. Obesity was observed among females at $22 \%$, among males at $17 \%$, we can assume that in this age group, women are more prone to gain excess weight than men.
When assessing the level of physical activity, it was found that $52 \%$ of the respondents do not engage in physical activity at all. About $28 \%$ engaged in physical activity less than 150 minutes a week, physical activity was not regular, mainly at the expense of walks and morning exercises. Only $20 \%$ of those studied had a sufficient and regular level of physical activity. Among females a sufficient level of PA was observed in $23 \%$, among males in $20 \%$ mainly due to health-improving physical exercises, weight-bearing walking, and online training. The most notable barriers to increasing the level of physical activity were pandemicrelated interference, the danger of going to public places, lack of desire, and lack of time (Tab. I).

A comparative analysis of quality of life indicators of young adults before the pandemic and during the COVID-19 pandemic was performed.

We found a significant decrease in the physical component of health quality of life of young people during the pandemic by $6 \%$ compared to the previous period $(p=0.033)$. The physical component of health is formed by scales that allow us to assess which causes can limit a person's physical activity. During the pandemic, there is a small but significant decrease in physical functioning of $4 \%(\mathrm{p}=0.007)$. During the pandemic, there is a significant $11 \%(\mathrm{p}=0.0002)$ decrease in physical condition-related role functioning compared to the previous period. Thus, the conditions during the pandemic cause limitations in the performance of certain daily activities, there are difficulties in performing these activities. There was no significant difference in pain intensity between the groups. The pandemic had a significant $(p=0.0004)$ effect on the general health score, as it was $10 \%$ lower than the previous 
period. Individuals of younger age considered themselves to be more morbid, more prone to developing disease, and were more likely to have a pessimistic view of their health during the pandemic (Tab. II).

The indicator of role functioning conditioned by emotional state was found to be $23 \%(\mathrm{p}=0.0001)$ lower during the pandemic, which confirms the negative impact of the pandemic on the emotional state of persons of young age. The indicator characterizing mood and the presence of depressive states, anxiety, negative emotions - mental health. We found a significant $(\mathrm{p}=0.0004)$ decrease in this indicator during the pandemic by $16 \%$. This indicates that young people during the pandemic are more prone to depressive states, they are more often disturbed by a feeling of nervousness, fatigue, lack of energy, a feeling of despair.

\section{DISCUSSION}

Coronavirus disease and the pandemic have become a global problem with unprecedented medical, economic and social consequences for society. The medical world community is concerned about the consequences of the COVID-19 pandemic, its impact on physical and mental health and quality of life of people of different ages $[9,10,12]$. According to the WHO definition: «Quality of life is a person's perception of his position in life, including physical, mental and social well-being, depending on the quality of the environment in which he lives, as well as the degree of satisfaction with a particular standard of living and other components of psychological comfort». In the structure of quality of life, lifestyle accounts for $50 \%$ and is a weighty factor influencing all components of quality of life. Restrictive pandemic measures and distance learning have a significant impact on the lifestyles of young people, also reflected in their quality of life $[13,14]$. The results of our study show a decrease in the quality of life of young people during the pandemic compared to the previous period, especially the index of role functioning conditioned by physical state, role functioning conditioned by emotions and the index of mental health. According to WHO, one in four adults worldwide does not meet the generally accepted levels of physical activity, while, we can assume that this rate has significantly worsened due to the pandemic and a number of restrictive measures [15]. Our study shows that only $20 \%$ of young people have adequate levels of physical activity. The new 2020 WHO guidelines emphasize that any amount of $\mathrm{PA}$ is better than nothing, but young people should still be encouraged to increase their PA levels [15]. Inadequate PA levels are also associated with a number of pandemic restrictive measures and perhaps it is the decline in PA that has led to a decrease in quality of life for young people, as these two factors are interrelated.

\section{CONCLUSIONS}

The COVID-19 pandemic, social distancing and quarantine restrictions made a significant impact on the quality of life of young adults, especially on indicators such as role functioning due to physical fitness, general health, mental health and the psychological component of health. In a pandemic environment, $80 \%$ of young adults do not have adequate levels of physical activity and in most cases this is due to the restrictive measures of the COVID19 pandemic.

\section{REFERENCES}

1. Warburton D.E., Bredin S.S. Reflections on Physical Activity and Health: What Should We Recommend ?. Can J Cardiol. 2016; 32(4): 495-504.

2. World Health Organization, Global Recommendations on Physical Activity for Health. 2011. http://whqlibdoc.who.int/ publications/2010/9789241599979_eng.pdf

3. Hegde S.M., Solomon S.D. Influence of Physical Activity on Hypertension and Cardiac Structure and Function. Curr Hypertens Rep. 2015;17(10):77. doi:10.1007/s11906-015-0588-3.

4. World Health Organization WH0. 2020. https://www.who.int/newsroom/fact-sheets/detail/physical-activity.

5. Piercy K.L., Troiano R.P., Ballard R.M. et al. The Physical Activity Guidelines for Americans. JAMA. 2018;320(19):2020-2028. doi:10.1001/ jama.2018.14854.

6. Ahmed M.Z. et al. Epidemic of COVID-19 in China and associated Psychological Problems. Asian J Psychiatr. 2020;51:102092.

7. Shanahan L., SteinhoffA., Bechtiger L. et al. Emotional distress in young adults during the COVID-19 pandemic: evidence of risk and resilience from a longitudinal cohort study. Psychol Med. 2020;1-10.

8. Blake H., Stanulewicz N., Mcgill F. Predictors of physical activity and barriers to exercise in nursing and medical students. J Adv Nurs. 2017;73(4):917-929.

9. Al Joboory S. et al. "Covid-19, les effets psychopathologiques de la pandémie" [COVID-19, the psychopathological effects of the pandemic]. Soins. Psychiatrie. 2020; 41: 12-15.

10. WHO. Mental health and psychosocial considerations during the COVID-19 outbreak. 2020. https://www.who.int/docs/default-source/ coronaviruse/mental-health-considerations.pdf

11. Stewart M. The medical Outcomes Study 36-item short-form health survey (SF-36), Australian Journal of Physiotherapy. 2007; 53(3): 208.

12. Carvalho V.0., Gois C.0. COVID-19 pandemic and home-based physical activity. J Allergy Clin Immunol Pract. 2020;8(8):2833-2834.

13. Shuval K., Leonard T., Drope J. et al. Physical activity counseling in primary care: Insights from public health and behavioral economics. CA Cancer J Clin. 2017;67(3):233-244.

14. Chughtai M., Gwam C.U., Mohamed N. et al. Impact of Physical Activity and Body Mass Index in Cardiovascular and Musculoskeletal Health: A Review. Surg Technol Int. 2017;31:213-220.

15. WHO. Coronavirus disease 2019 (COVID-19) Situation report-93. 2020. https://www.who.int/docs/default-source/coronaviruse/situationreports/20200422-sitrep-93covid-19.pdf?sfvrsn=35cf80d7_4 .

\section{ORCID and contributionship:}

Mariia A. Ovdii: 0000-0002-0163-7914 ${ }^{\text {A, D, F }}$

Kateryna M. Solomakha: 0000-0001-7944-3442 ${ }^{B, D}$

Mykola O. Yasynetskyi: 0000-0002-4426-1769 D, F

Nataliia P. Ponomarenko: 0000-0002-6899-2486 A, C, E

Yurii M. Rydzel: 0000-0002-1812-0436 ${ }^{\text {, C }}$

\section{Conflict of interest:}

The Authors declare no conflict of interest. 


\section{CORRESPONDING AUTHOR}

Mariia A. Ovdii

0.0. Bogomolets National Medical University

34A Mykhailo Hrushevskoho st., 02000 Kyiv, Ukraine

tel: +380503874590

e-mail: rehability13@gmail.com

Received: 21.10 .2020

Accepted: 13.04.2021

A - Work concept and design, B - Data collection and analysis, C - Responsibility for statistical analysis,

D-Writing the article, $\mathbf{E}$ - Critical review, F-Final approval of the article 